\title{
SENSO COMUM E ESTEREOTIPIA NAS PRÁTICAS DE LEITURA*
}

\author{
DyLIA LYSARDO-DIAS, \\ da Universidade Federal de São João del-Rei
}

\begin{abstract}
REsUMO: Este artigo apresenta uma reflexão sobre as representações sociais acerca da leitura e de sua prática sob uma perspectiva discursiva. Considerando a natureza sócio-histórica da leitura, focaliza-se a sua relação com a estereotipia e a consequente naturalização de certas visões, naturalização que desconsidera a dinamicidade da vida social e a ação dos indivíduos como sujeitos únicos que transitam entre o novo e o diferente, ressignificam o jádito a partir da sua subjetividade e das relações intersubjetivas nas quais se inscrevem. Os estereótipos, entendidos como esquemas culturais que instituem uma percepção coletiva, mas nem por isso imutável, desempenham um importante papel no processo de leitura, já que o poder de evocação do estereótipo tem a ver com o conhecimento prévio que o leitor possui de seu próprio entorno e com a sua capacidade de perceber a presença de certos universos de referência.
\end{abstract}

Palavras-chave: Leitura. Estereótipos. Senso comum. Dialogismo.

Ler é uma viagem. Ler é descobrir o mundo. Ler é um barato.

Esses clichês sobre a leitura, recorrentes prioritariamente em campanhas que visam seu incentivo, revelam imagens em torno dessa atividade, cuja valorização está diretamente relacionada à elitização histórica que caracteriza seu aprendizado até, pelo menos, o século XIX. A imagem difundida é de prazer e descoberta gratuita, sem a exigência de nenhum labor ou esforço.

\footnotetext{
* Artigo recebido em 19/10/2011 e aprovado em 6/12/2011.
} 
O senso comum consagra igualmente afirmativas do tipo "o brasileiro lê pouco, o brasileiro lê mal, as crianças hoje em dia não leem como antigamente", que são internalizadas e alimentam a impressão da decadência da leitura hoje no Brasil. Há um certo saudosismo como se os índices de analfabetismo não estivessem diminuindo, ainda que lentamente. É realidade ainda o número crescente, mas não ideal, de crianças brasileiras que têm acesso à escola, mesmo que a evasão continue atingindo índices elevados.

No âmbito educacional, o propalado fracasso generalizado da escola brasileira, outro chavão que nos assola, é atribuído, sobretudo, à ineficácia das aulas de português, mais pontualmente ao pouco desenvolvimento da leitura. É dado como sendo de responsabilidade dos professores de português o fato de os alunos serem tão mal avaliados em exames que medem a competência de leitura. Acredita-se que esses alunos também escrevem de forma precária porque leem mal e pouco. A crença é que a leitura não acontece quantitativa nem qualitativamente como deveria.

Todas essas ideias pré-construídas sobre a leitura, na hipergeneralização que encerram, descaracterizam a sua dimensão de processo discursivo, que se realiza a partir da diversidade de modos de relação que o sujeito pode estabelecer com as diferentes textualidades. Ao instituir valores, no caso citado sobre a leitura, tais enunciados preconizam julgamentos que vão sendo tomados como evidências e que geram outras percepções, sem que haja espaço para considerar a dinamicidade dos padrões da vida social e o surgimento de novas tecnologias de informação e comunicação. Eles emergem como construções coletivas que forjam e cristalizam um modo de apreender uma dada realidade, que é amplamente difundido e aceito como verdade.

A naturalização que cerca tais visões prévias e os dizeres que as materializam impedem, às vezes, de considerar os novos tipos de texto, os procedimentos de leitura específicos que eles mobilizam e os recentes modos e hábitos de leitura impostos pela configuração social contemporânea.

Tal configuração encontra-se inserida no que Bauman (2001) chama de "modernidade líquida", momento que vivemos e que é caracterizado como um processo de "liquefação" e de dissolução de certos padrões instituídos. Segundo ele, estamos diante de um mundo fragmentado, onde tempo e espaço apresentam uma nova modulação, já que "o que conta é o tempo, e não o espaço" (p. 8). O movimento, a instantaneidade e o "aqui e agora" marcam a contemporaneidade como a época da pluralidade e da ruptura. Isso vale para a compreensão da leitura, que hoje ultrapassa os modelos impostos pelos mecanismos de alfabetização em favor das práticas de 
letramento. Para além do dualismo decodificar-atribuir sentidos, ler é um processo de interlocução entre sujeitos historicamente situados, que fazem uso de elementos de diferentes ordens.

Trata-se de um investimento que o indivíduo faz como sujeito historicamente situado e que o leva a transitar entre o que é da ordem do linguístico e o que é da ordem do social, sendo que um não pode prescindir do outro. Como sujeito que é, o leitor mobiliza um conjunto de ações que se inter-relacionam, sem que, por exemplo, o aspecto cognitivo seja mais importante que $o$ aspecto cultural. Assim, qualquer dizer sobre a leitura envolve a especificação do tipo de leitura ao qual se refere, considerando a diversidade de situações enunciativas e o fato de a leitura ser um processo.

\section{Há "Leituras" e "Leituras"}

Muito do que se fala sobre a leitura decorre do fato de ela ser tratada como um mesmo tipo de ação sempre igual e que se repete. Entretanto, lê-se por diferentes motivos e, por isso, de diferentes modos. Há, por exemplo, uma leitura de cunho funcional, que está relacionada ao nosso cotidiano e que nos coloca diante de sistemas semióticos diversos, isoladamente (se é que isso é possível) ou articulados, para resolvermos questões básicas. Precisamos ler a placa com o nome da rua para acharmos o consultório médico; ler os comandos do computador para acessar determinado site com a programação do cinema no final de semana; ler os preços no supermercado e as etiquetas dos produtos para escolher o produto que nos é mais conveniente. É uma leitura que, se não coloca em risco nossa sobrevivência, incide diretamente sobre a nossa qualidade de vida e satisfação pessoal. Ela faz parte da nossa vida diária e se impõe em meio a outras ações cotidianas banais.

Há a leitura escolar, ou escolarizada, que se insere no âmbito de uma instituição de ensino: é aquela que será avaliada, formalmente ou não, em termos de desempenho. É uma leitura que deve satisfazer a demanda do outro. O professor-avaliador determinará se ela foi correta ou não. Por isso, a escolha do material de leitura, da maneira como ela se dará e dos critérios para determinar sua adequação é papel daquele a quem é atribuída a competência do saber. Entre o sujeito-leitor e o texto, há o professor como mediador dessa leitura: é ele o sujeito destinatário.

Há, ainda, uma leitura lúdica, de caráter espontâneo, pois, sendo o texto literário ou não, é buscado como fonte de distração. Não tem um objetivo dado pelo outro, nem uma demanda pragmática imediata, mas atende a um desejo ou motivação individual do sujeito de fruição ou de satisfação estética. É aquela leitura como "uma fonte inesgotável de prazer", 
nos dizeres de Carlos Drummond de Andrade, que envolve de forma mais aguda o artístico e o potencial criativo dos sujeitos.

Essa categorização, estabelecida em função da finalidade última da leitura para o sujeito leitor, não perde de vista que toda e qualquer leitura pode, ou não, promover ou contribuir para uma visão crítica e ampliar a formação do cidadão, dependendo da maneira como o leitor se insere no texto e do impacto que esse último gera. Graças à articulação que se constrói entre a materialidade linguística do texto e as circunstâncias ditas extralinguísticas das quais ele emerge e que lhe conferem uma existência única e irrepetível, é possível obter uma percepção mais apurada de certas formas de falar/pensar/ agir socialmente instanciadas. Essa é a dimensão formadora e democrática da leitura na medida em que ela contribui para o desenvolvimento pessoal e para o exercício da cidadania.

Portanto, ler é sempre uma atividade: pode ser prazerosa, um "verdadeiro barato", ou uma "viagem incrível"; mas pode requerer muito esforço, às vezes inconsciente, às vezes deliberado, e até planejado. Como uma ação de sujeitos, ler apresenta várias dimensões que não se excluem e cuja globalidade sinaliza as relações entre linguagem e sociedade.

Os brasileiros podem ler com pouca frequência as obras literárias ditas clássicas, mas a expansão do mercado editorial, com o surgimento constante de novas revistas que atendem aos mais diversos segmentos da sociedade, aponta para o crescimento desse tipo de leitura, uma vez que os novos títulos da imprensa só permanecem no mercado se estiverem gerando lucro.

A escola hoje tem que lidar com os vários tipos de letramento, como o visual e o digital, por exemplo. As novas textualidades decorrentes da expansão dos sistemas tecnológicos de comunicação criam outras formas de subjetivação e de sociabilidade, que exigem novas intervenções pedagógicas.

Portanto, julgamentos sobre as práticas de leitura na nossa sociedade demandam um olhar atento e problematizador que vai além do senso comum, que banaliza a leitura e ignora a complexidade dos modos de inserção do indivíduo na sociedade letrada. A naturalização de certas visões desconsidera a dinamicidade da vida social e a ação dos indivíduos como sujeitos únicos que transitam entre o novo e o diferente, ressignificam o já-dito a partir da sua subjetividade e das relações intersubjetivas nas quais se inscrevem.

\section{A LEITURA COMO PRÁTICA DISCURSIVA}

O processo de leitura é dependente das referências socioculturais subjacentes e constitutivas de cada situação de interação verbal, pois um texto se enquadra não apenas em sistematicidades formais e organizacionais, mas 
também em esquemas referenciais e relacionais já estabilizados. Ele acontece a partir de um saber cultural comum e, por isso, instaura um movimento de percepção da conformidade ou da subversão de esquemas já conhecidos, que são redimensionados para comportar novos/outros sentidos. Esse saber cultural atua como uma espécie de suporte da leitura, sendo responsável por uma relativa estabilidade de sentido junto ao contexto de recepção. Assim sendo, as possibilidades de um "novo dizer" são, de alguma forma, demarcadas pela relação que se estabelece com o conhecido e o previsível.

Se o sentido resulta de um trabalho do sujeito leitor, esse trabalho é tributário de um sistema de significações prévias, tanto em termos de redes estruturais quanto em termos de universos de referência e esquemas conceituais, fatores que interferem na legibilidade do texto. Essa relação é atualizada de maneira singular a cada circunstância de uso quando o sujeito leitor projeta hipóteses de leitura a partir da materialidade que tem diante de si e dos estereótipos que mobiliza. Mas o que seriam esses estereótipos?

Em uma visão discursiva, os estereótipos são por nós entendidos como representações socialmente partilhadas (LYSARDO-DIAS, 2006) que funcionam como pressupostos culturais comuns a uma coletividade e que lhes conferem uma relativa unidade. Não se trata de algo fixo, mas da estabilização de certos conhecimentos que emergem de um suposto senso comum e se fixam como um código cultural. Os estereótipos são formas convencionalizadas de apreensão do real que os sujeitos vão internalizando e difundindo; são esquemas culturais que instituem uma percepção coletiva, mas nem por isso imutável.

Daí, eles desempenharem um importante papel no processo de leitura, quando o sujeito reconhece algo que lhe é familiar e processa aquilo que lhe parece estranho, em um jogo de conformidade/não-conformidade ao que é apresentado. $O$ sujeito leitor é ativo e atua com sua subjetividade de ser histórico, envolvendo-se e inserindo-se no texto na sua singularidade de sujeito interpretante que se constitui com base na sua posição enunciativa.

Os efeitos de sentido do estereótipo e sua funcionalidade dependem não apenas da relação que guardam com uma situação histórica, mas igualmente da competência do destinatário, que só pode identificar um estereótipo se este fizer parte da sua bagagem cultural. O poder de evocação do estereótipo tem a ver com o conhecimento prévio que o leitor possui de seu próprio entorno e com a sua capacidade de perceber a presença de certos universos de referência.

Em uma perspectiva bakhtiniana, a leitura pressupõe uma "compreensão responsiva" na qual diferentes vozes se entrecruzam. Ela é dialógica, 
pois só pode ser concebida como uma interlocução entre um sujeito enunciador e um sujeito leitor. Há um processo de interlocução entre a cultura vivenciada por todos e a experiência e percepção singular de cada indivíduo. Por isso, Soares (2000, p. 18) afirma que "a leitura não é um ato solitário; é interação entre indivíduos, e indivíduos socialmente determinados". É na interação entre sujeitos socialmente inscritos e uma materialidade igualmente histórica que os sentidos emergem. Dialogam entre si o sujeito autor do texto e as condições enunciativas nas quais ele se inscreve, o sujeito-leitor e seu universo de crenças e saberes na produção de significados.

Como a leitura é um processo inserido em uma realidade históricocultural, ou seja, "implica a percepção entre texto e contexto", conforme nos lembra Paulo Freire $(1989$, p. 9), a virtualidade dos estereótipos encontra-se limitada por um contexto social que vincula uma referência coletivamente codificada a um momento/época precisa. Todo estereótipo existe dentro das condições de produção que o engendraram. É nesse sentido que se pode postular a dimensão ideológica dos estereótipos: eles são portadores de uma forma possível de compreensão do mundo social e oferecem modelos culturais a partir dos quais os membros de um grupo estabelecem suas relações, de poder, com os outros membros e vivenciam a "realidade". Pela repetição, eles instituem hegemonias que se relacionam a formas de poder. Dessa maneira, os estereótipos materializam os valores próprios de um grupo social e sua identificação envolve, necessariamente, um questionamento desses valores. O sujeito leitor, estando inserido nesse universo social, é um sujeito histórico, que lê a partir dessa sua inscrição.

Mas um texto só existe em relação a outros textos, dialogando com um já-dito e inscrito em um horizonte de expectativas a partir do conjunto de crenças e saberes coletivos. A relação com um texto tem a ver com esse movimento interdiscursivo e intradiscursivo que se estabelece entre os dizeres, os discursos e os gêneros.

Aliás, a questão dos gêneros se torna fundamental para se pensar a leitura como uma ação entre sujeitos da linguagem, pois, como nos indica Bakhtin (1992), os enunciados pertencem a dadas esferas sociais de comunicação em função da especificidade da troca verbal. Os gêneros remetem a processos enunciativos diversos, já que a historicidade é traço constitutivo do enunciado e o leitor age na sua singularidade de sujeito inserido em uma dinâmica social, que o constitui como tal. Antes de entrarem para a escola, as crianças já têm um conhecimento intuitivo sobre os gêneros, diferenciando, conforme a vivência e a socialização, por exemplo, um livro de um jornal. Dentro da diversidade de práticas comunicativas, esses materiais 
vão sendo associados a configurações específicas, tendo em vista certas regularidades. A economia cognitiva que essa operação realiza baseia-se nas experiências anteriores de leitura.

Assim, os gêneros remetem à relação que se estabelece entre parâmetros linguístico-discursivos e o circuito comunicacional. Envolve saberes enciclopédicos, saberes textuais e saberes relativos ao funcionamento das interações sociais. Há gêneros mais estereotipados, como a correspondência comercial, por exemplo, e outros bem mais imprevisíveis, como aqueles relacionados à literatura. Entre eles, há uma série de produções que transitam entre dois polos, podendo se situar mais próximas da padronização ou mais próximas da singularidade.

Ler é situar o texto em relação ao gênero e aos gêneros a que pertencem, considerando a hibridização, a transgressão e o surgimento de novos gêneros. Nesse movimento de combinações do qual emergem os gêneros, a importância das várias agências de letramento sinaliza que o multiletramento é um processo contínuo de desenvolvimento do cidadão.

Charaudeau (1999) considera que os gêneros remetem a processos de socialização do sujeito por meio da linguagem e da linguagem por intermédio do sujeito, ser individual e coletivo. Para ele, a normalização dos comportamentos, do sentido e das formas se constrói pelo uso do sujeito, que os registra em sua memória. Por isso, o autor postula a existência de três memórias: uma memória dos discursos, que se refere aos conhecimentos e crenças do sujeito; uma memória das situações de comunicação, que diz respeito à representação das situações de comunicação; e uma memória das formas de signos, que corresponde às maneiras de dizer, o savoir dire.

Nesse sentido, ser leitor vai além do conhecimento de um código, pois demanda lidar com diferentes dispositivos, articulando essas memórias no que elas representam em termos de conhecimento já ressignificado pelo sujeito.

Os saberes prévios, mais ou menos estereotipados, são utilizados não apenas como estratégia de produção de sentido pelo sujeito leitor, mas também como elemento que integra todo dizer/fazer do ser humano. Como referência sociocultural partilhada, eles integram a dimensão interdiscursiva inerente às várias textualidades, cujo valor ideológico advém do que representam como imagem coletiva pré-construída para um grupo social. Esses saberes prévios funcionam como elemento de coesão entre os sujeitos, que gera um sentimento de pertença a esse grupo social.

Ler é, em última instância, relacionar sistemas de significação prévios àquele novo tecido textual que se apresenta a partir de uma sempre nova 
situação enunciativa. A percepção desse movimento de diálogo é que leva o leitor a penetrar nos liames ideológicos do texto, resgatando sua historicidade e sua inscrição cultural. O estereótipo é assim fator de legibilidade por viabilizar o acesso a um dizer textualmente organizado.

\section{CONSIDERAÇÕES FINAIS}

Se para se converter em uma prática significativa para os alunos a leitura precisa ser trabalhada como uma atividade contextualizada e relacionada às circunstâncias de produção do discurso, o estudo e o reconhecimento dos estereótipos inscritos em um texto contribuem para que ela seja um exercício de ressignificação do "real". Assim, a dimensão social e o caráter dialógico da linguagem deverão ser percebidos no cotidiano da sala de aula e a leitura terá efetivamente uma dimensão de atividade de interação. Ao invés de ser"consumido passivamente" pelos alunos, o texto desencadeará uma reflexão sobre os pressupostos culturais e sua naturalização no tecido social.

Cada época tem seus estereótipos, assim como cada grupo social constrói coletivamente toda uma gama de saberes comuns. O estereótipo é universal para uma coletividade, que, ao longo de sua história, preserva uns e institui outros que acompanham o seu desenvolvimento. Assim sendo, por mais que se possa associar o estereótipo àquilo que já está previamente definido, ele não é estático dentro do tecido social do qual faz parte integrante: ele pode ser renovado e ganhar novos contornos, assim como pode ser modificado, acompanhando a dinâmica da vida em sociedade e suas novas demandas.

Cabe aos professores desenvolver a habilidade de leitura e a capacidade de análise crítica dos seus alunos de produzir sentidos, levando-os a identificar em um texto os esquemas já cristalizados, as imagens familiares e os modelos sociais com os quais dialogam, seja para confirmar, seja para questionar. Como afirma Geraldi (1996), a leitura é um espaço de confrontos e rupturas, de encontros de pontos de vista. Logo, ser leitor é ser capaz de compreender um texto nas suas relações com o seu espaço cultural, é ter acesso ao funcionamento ideológico da linguagem, é captar o movimento contínuo de aproximação e de distanciamento dos discursos outros que nos constituem. 


\section{COMMON SENSE AND STEREOTYPE IN READING PRACTICE}

ABSTRACT: This paper reflects on social representations about reading and its practice from a discursive perspective. Considering the socio-historical nature of reading, this study focuses on the relationship between reading and stereotypes and the consequences that this relationship poses for the naturalization of certain views. This naturalization does not consider the dynamic characteristic of social life and the participation of human beings as unique subjects who move between the new and the different, resignifying what has already been said arising out of its subjectivity and the inter-subjective relations within it. Stereotypes, understood as cultural schemas constituting an overall perception which is by no means immutable, play an important role in the reading process, since the power of stereotype for evoking has to do with the previous knowledge the reader has of his/her surroundings and his/her capacity to perceive references which are universal.

KEYWORDS: Reading. Stereotypes. Common sense. Dialogism.

\section{REFERÊNCIAS}

AMOSSY, Ruth; PIERROT, Anne H. Stéréotype et clichés: langue, discours, societé. Paris: Nathan, 1997.

AMOSSY, Ruth. Les idées reçues, sémiologie du stéréotype. Paris: Nathan, 1991.

BAKHTIN, Mikhail (VOLOCHINOV) (1929). Marxismo e filosofia da linguagem. São Paulo: Hucitec, 1979.

BAKHTIN, Mikhail. Estética da criação verbal. São Paulo: Martins Fontes, 1992.

BAUMAN, Zigmunt. Modernidade líquida. Rio de Janeiro: Jorge Zahar, 2001.

CHARAUDEAU, Patrick. Visées discursives, genres situationnels et construction textuelle, 1999. (Mimeo).

CORACINI, Maria José. Subjetividade e identidade do professor de português. Trabalhos de Linguística Aplicada, n. 36, 2002.

DE CARLO, Maddalena. Stéréotype et identité. Éla: revue de didactologie des languescultures, v. 107, p. 278-290, jul./set. Paris, 1997.

DUFAYS, Jean-Louis. Stéréotypes et lecture. Liège: Mardaga, 1994.

FREIRE, Paulo. A importância do ato de ler: em três artigos que se completam. São Paulo: Cortez, 1989.

GERALDI, João Wanderley. Linguagem e ensino: exercício de militância e divulgação. São Paulo: Mercado de Letras, 1996.

LYSARDO-DIAS, Dylia. O discurso do estereótipo na mídia. In: EMEDIATO, Wander et al. (Org.). Análise do discurso: gêneros, comunicação e sociedade. Belo Horizonte: Núcleo de Análise do Discurso, Pós-Lin/FALE/UFMG, 2006. p. 25-36. 
SOARES, Magda Becker. As condições sociais da leitura: uma reflexão em contraponto. In: ZILBERMAN, R.; SILVA, Ezequiel T. (Org.). Leitura: perspectivas interdisciplinares. 5. ed. São Paulo: Ática, 2000. p. 18-29.

DYLIA LYSARDO-DIAS é professora associada da Universidade Federal de São João Del-Rei, MG, onde integra o corpo docente do Mestrado em Letras. Desenvolve pesquisas na área de Análise do Discurso, dedicando-se atualmente ao Projeto de Pesquisa, Ensino e Extensão intitulado Escritas (auto)biográficas: aspectos culturais, discursivos e literários. E-mail: dylia@ufsj.edu.br 